\title{
Description d'un nouveau Formicide [Hys.] de l'Afrique occidentale
}

\author{
par le $D^{\mathrm{r}}$ F. SAntschi.
}

Xiphomyrmex occidentalis, n. sp. - $\$$. Long. 3,̋̈ mm. Noir brunâtre. Mandibules, antennes, membres et extrémité du gastre brun noirâtre. Lisse et très luisant. Côtés de la tête et du méso-épinotum

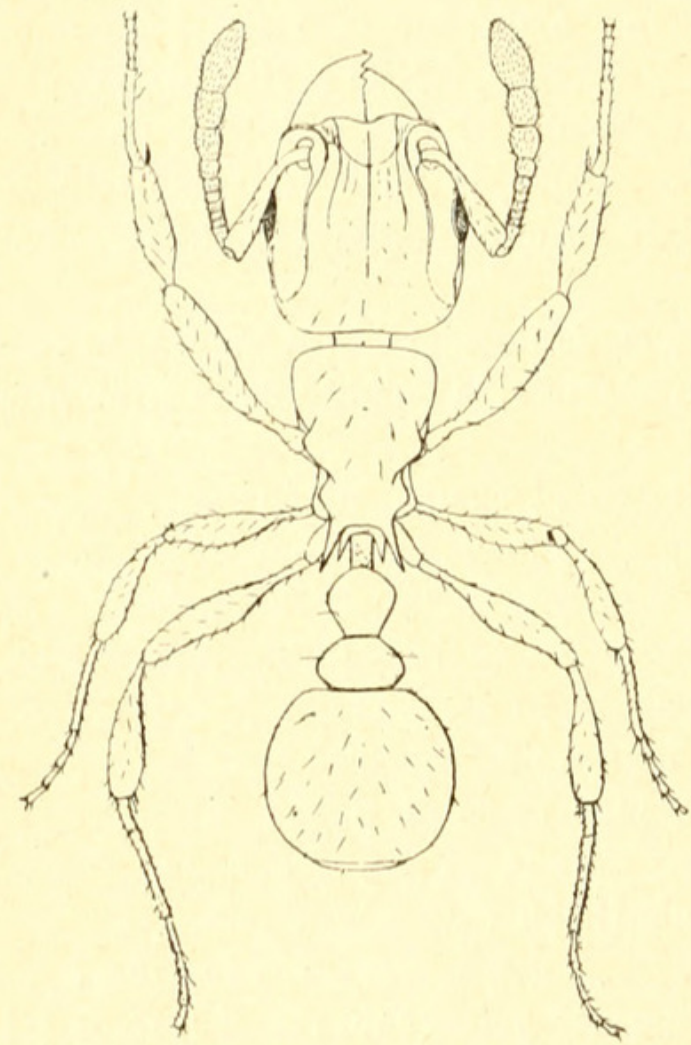

Fig. 1. - Xiphomyrmex occidentalis, n. sp. réticulés-ridés. Partout une pilosité très fine, longue et assez espacée. Pubescence très fine et clairsemée, plus dense sur les tibias et les antennes.

Tête rectangulaire, plus longue que large d'un sixième; les côtés peu convexes, le bord postérieur presque droit, avec les angles arrondis. Yeux assez convexes, aussi grands que le quart des côtés de la tête au milieu desquels ils sont placés. Les arêtes frontales atteignent le cinquième postérieur de la tête; elles divergent fortement dans leur tiers antérieur et postérieur, deviennent subparallèles dans le tiers moyen et limitent un scrobe assez profond où le scape peut se coucher dans toute sa longueur. Épistome peu convexe, concave de droite à gauche, avec une échancrure au bord antérieur; il est parcouru par trois fortes rides parallèles qui se prolongent, les externes, jusqu'à la hauteur des yeux, les médianes jusqu'au bord occipital. Mandibules lisses, larges, de 7 à 8 dents. Scape épais, atteignant le cinquième postérieur de la tête. Articles 2 à 6 du funicule deux à trois fois plus épais que longs (le $7^{\text {e }}$ d'un tiers plus épais que long). Massue de trois articles. Thorax sans sutures, mais échancré latéralement a leur niveau. Entre ces échancrures, le thorax est bordé et saillant. Pronotum bordé en arc antérieurement, avec les angles mousses, mais assez marqués. La face basale de l'épinotum plus large en avant que longue, 


\section{$2 \mathrm{BHL}$ Biodiversity Heritage Library}

1916. "Description d'un nouveau Formicide de I'Afrique occidentale." Bulletin de la Société entomologique de France 1916, 50-50. https://doi.org/10.5962/bhl.part.24165.

View This Item Online: $\underline{\text { https://www.biodiversitylibrary.org/item/37021 }}$

DOI: https://doi.org/10.5962/bhl.part.24165

Permalink: https://www.biodiversitylibrary.org/partpdf/24165

\section{Holding Institution}

Smithsonian Libraries

\section{Sponsored by}

Smithsonian

\section{Copyright \& Reuse}

Copyright Status: NOT_IN_COPYRIGHT

This document was created from content at the Biodiversity Heritage Library, the world's largest open access digital library for biodiversity literature and archives. Visit BHL at https://www.biodiversitylibrary.org. 